\title{
Desenvolvimento de uma plataforma web de apoio ao gerenciamento de acidentes de trânsito
}

\author{
Adilso Nunes de Souza ${ }^{1}$, Francisco Dalla Rosa ${ }^{2}$
}

\begin{abstract}
Resumo: A inexistência de informações que caracterizam o trânsito nos municípios brasileiros tem dificultado a realização de ações/projetos para a melhoria do fluxo e diminuição de acidentes nas vias. Dessa forma, este estudo apresenta uma plataforma para a coleta, armazenamento e análise de dados detalhados dos acidentes de trânsito, através de um aplicativo informatizado e vinculado à internet. Utilizou-se a cidade de Passo Fundo/RS como local piloto para teste desse sistema, devido à disponibilidade dos órgãos gestores em fornecer os dados dos registros de acidentes de trânsito. A implementação do banco de dados permitiu centralizar e armazenar todas as informações, para que sejam utilizadas como pesquisa de informação e favoreçam no processo de tomada de decisão pelas autoridades competentes na melhoria do sistema viário. Além disso, o sistema está interligado com as APIs do Google, resultando numa rápida análise geoespacial da distribuição e da classificação dos acidentes ocorridos dentro de um determinado período.
\end{abstract}

Palavras-chave: Acidentes de trânsito; Coleta de dados de acidentes; Sistema de Gerenciamento de Acidentes de Trânsito.

\begin{abstract}
One of the many problems encountered by traffic managers personal in Brazil is the lack of an organized georeferenced information about traffic accidents. Consequently, the implementation of projects in order to decrease traffic accidents are hampered by Brazilian's database. Thus, this paper presents a platform for collecting, storing and analyzing detailed data of traffic accidents through a computerized application. The city of Passo Fundo/RS was chosen to be the pilot site for testing this system due to the traffic management department partnership. The implementation of the database allowed centralizing and storing all the information, which could improve the Traffic Decision Support System (TDSS). Furthermore,
\end{abstract} the system has been integrated with Google APIs, resulting in fast geospatial analysis of traffic accidents.

Keywords: Traffic accidents; Accident data collection; Traffic Accident Management System.

\section{INTRODUÇÃO}

O crescimento populacional e a forma da sociedade viver e se locomover, aliados às facilidades de crédito nas últimas décadas para adquirir automóveis, vêm desencadeando o aumento da frota de veículos no Brasil. Segundo o Departamento Nacional de Trânsito (DENATRAN, 2015), ao final do ano de 2014 o Brasil contava com uma frota de veículos superior a 86,7 milhões de unidades. Considerando os dados da frota de veículos e da projeção da população Brasileira em 2014 (IBGE, 2015), o Brasil possui uma taxa de 2,4 habitantes por veículos, sendo que em várias cidades essa razão diminui consideravelmente.

Associado ao crescimento da frota de veículos no Brasil observa-se o incremento da taxa de acidentes de trânsito nos últimos anos. Segundo dados apresentados por WAISELFISZ (2013) o número médio de acidentes de trânsito envolvendo vítimas fatais nos três últimos anos (20112013) foi maior que 27000 registros enquanto que no Rio Grande do Sul ultrapassou a média de 2100 ocorrências no mesmo período. Nesse caso não está sendo contabilizado o número de acidentes que tiveram somente danos materiais, caso fosse, este número é consideravelmente maior.

Em muitos locais no Brasil o registro desses acidentes tem sido realizado de forma manual, o que dificulta muitas vezes o preenchimento, armazenamento e análise dos

\footnotetext{
${ }^{1}$ Adilso Nunes de Souza, Instituto Federal Sul-Rio-Grandense campus Paso Fundo - IFSUL. (adilso.souza@passofundo.ifsul.edu.br)

2 Francisco Dalla Rosa, Programa de Pós-Graduação em Engenharia Civil e Ambiental. Universidade de Passo Fundo - UPF. (f.dallarosa@gmail.com)
}

Manuscrito recebido em 15/12/2015 e aprovado para publicação em 23/07/2015

Este artigo é parte de TRANSPORTES v. 23, n. 3, 2015. ISSN: 2237-1346 (online). DOI: 10.14295/transportes.v23i3.876. dados posteriormente. Esse cenário colabora com o desenvolvimento de um ambiente onde as informações ou índices coletados são redundantes ou pouco confiáveis. Nesse sentido, os dados devem ser coletados e armazenados, propiciando diferentes níveis de interação com um público efetivamente interessado em seus conteúdos (ex. ELMASRI, 2005), implantando-se estratégias adequadas a serem tomadas frente à crescente demanda em infraestrutura. Assim, o grande volume de dados que é manipulado, necessita do auxílio de ferramentas informatizadas como é o caso dos sistemas de banco de dados (BD). Tais surgiram em resposta aos métodos mais antigos de organização de dados, como fichas em papel, planilhas eletrônicas e arquivos textos.

A proposta de modelos para monitoramento de acidentes de trânsito baseados em linguagem UML e utilizando-se uma plataforma GIS (Geographical Information System) tem sido abordada recentemente (ex.: Ansari e AlShabi, 2012). A partir do uso desse sistema é possível conceder diferentes níveis de acesso de acordo com a função de cada membro do órgão fiscalizador (Policiais, Gestores, Órgãos de Saúde, População, outros). Além disso, essas ferramentas permitem apoio à tomada de decisões realizadas pelos gestores em função da flexibilidade vinculada na análise posterior dos dados coletados.

No Brasil, deve-se destacar os esforços na implementação de rotinas para cadastro e análise de ocorrências no trânsito, entre elas: SIGETRANS (FRANÇA et al., 2011); SIAT-FOR (QUEIROZ et al., 2003); e eBRAT (EBRAT, 2013). Entre os sistemas citados, somente o SIGETRANS possui um vínculo com a interface Google. Por outro lado, observando-se os dados apresentados junto ao International Road Traffic and Accident Database (IRTAD, 2014), o Brasil ainda não possui de forma detalhada as ocorrências de 


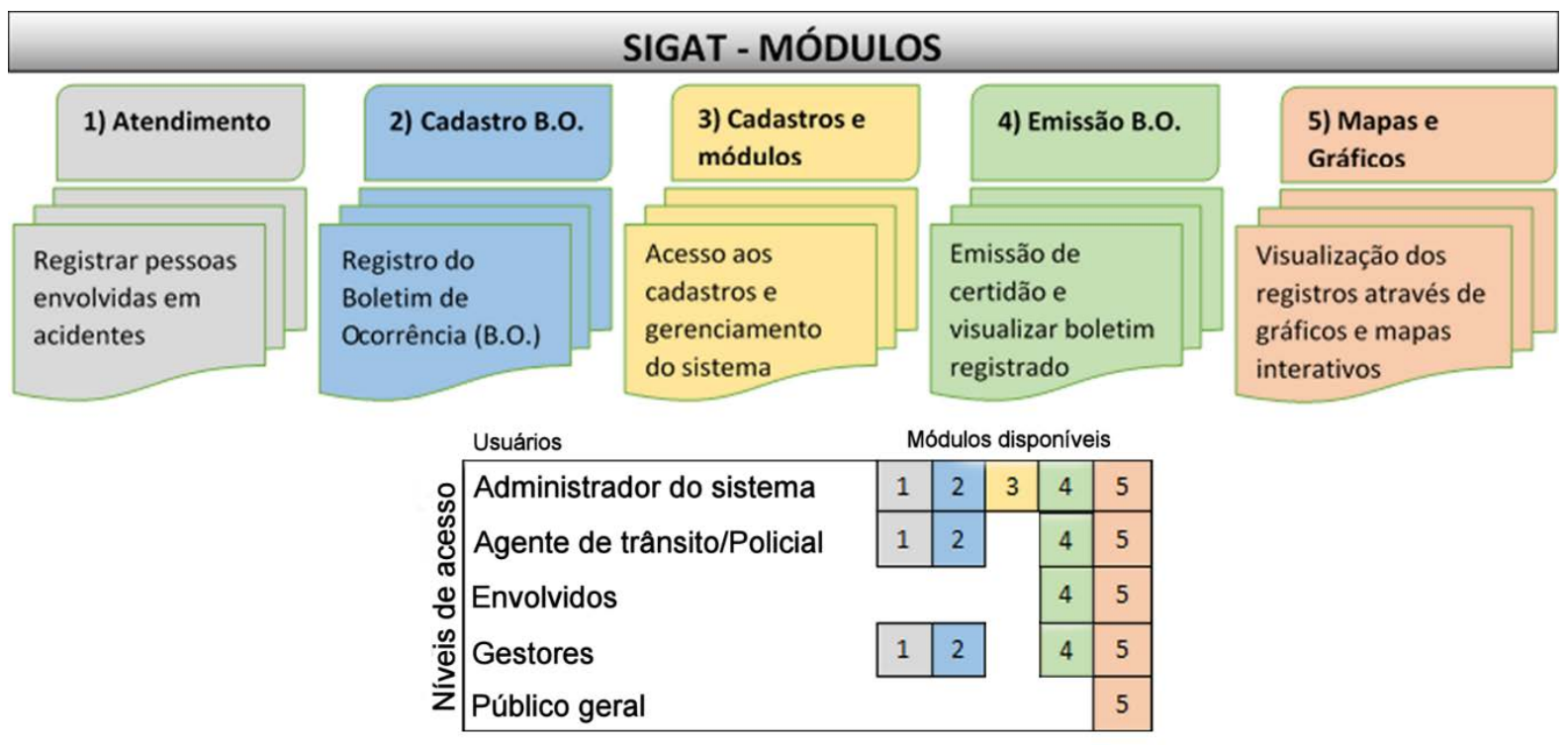

Figura 1. Definição dos níveis de permissão dos usuários do sistema

acidentes de trânsito. Nesse contexto, a elaboração de ferramentas como a desenvolvida nesse estudo é de grande importância, principalmente quando se vislumbra, do ponto de vista de planejamento e como um sistema de apoio, a tomada de decisão por órgãos gestores. Considera-se nesse caso como tomada de decisão todas as ações técnicas, fiscais e educacionais que visem melhorar a segurança no trânsito.

Além desses sistemas podem ser citados também os apresentados pelo Missouri State Highway Patrol (US), California Highway Patrol (US) e Florida Highway Patrol (US). Outro sistema considerado inovador foi o apresentado pela International Road Federation - IRF (2012). Trata-se de uma solução para gerenciamento de dados de acidentes desenvolvido na Índia. O sistema informatizado recebeu a denominação de RADAR - Road Accident Data Recorder Application, no qual a solução é baseada no fato de que os acidentes são eventos de múltiplos fatores, sendo necessário analisar adequadamente o quadro completo e detalhado sobre as causas e os resultados.

\section{MÉTODO}

\subsection{Estrutura do banco de dados e desenvolvimento da plataforma mobile}

O sistema desenvolvido constitui-se de uma plataforma com acesso por dispositivos mobile (Celulares/Smartphones/Tablets/etc.) e por equipamentos do tipo desktops e notebooks (Figura 02). No primeiro caso, o uso de dispositivos mobile foi pensado com o intuído de ser utilizado como uma ferramenta de campo, uma vez que o mesmo apresenta uma maior versatilidade durante o seu uso. Também, o sistema mobile apresenta a grande vantagem de possuir sensores de posicionamento global, como o GPS através do qual se tem a possibilidade de registro das informações, seguindo um padrão georreferenciado. Concomitante ao uso do sistema GPS/GLONASS, os dispositivos mobile (mobile) podem se utilizar do sinal provindo das antenas de telefonia, os quais, através das redes de dados, possibilita o registro com identificação da via onde o fato ocorreu com relativa acurácia.
Além das coordenadas geográficas, são requisitadas informações sobre as características de cada acidente, por meio das quais é possível identificar diferentes parâmetros relacionados à situação da via, veículo, horário e clima, bem como traçar um breve perfil dos envolvidos na ocorrência. Todos os dados coletados são enviados via conexão por telefonia móvel a um banco de dados, onde tais parâmetros podem ser acessados posteriormente em outros dispositivos, como estações de trabalho.

Dessa forma, é possível garantir que o sistema informatizado para coleta de dados e registro dos acidentes de trânsito ocorridos esteja disponível aos agentes de trânsito, polícias Militar/Civil e demais envolvidos na operação, por meio de aparelho móvel de fácil acesso e de um aplicativo informatizado. Além disso, o sistema pode operar em tempo real, ou seja, possibilitando que manobras para coordenação do trânsito possam ser emitidas através de uma central de atendimento com o intuito de reduzir as linhas de congestionamento e facilitar a evacuação das vítimas de forma ágil e segura.

Os usuários do sistema possuem níveis de permissão de acesso para cada módulo do sistema, sendo possível definir qual ação que cada usuário poderá realizar dentro do sistema como apresentado na Figura 1. Observa-se que o sistema possui diferentes escalas de acesso, onde o administrador possui o nível mais amplo, o qual é capaz de alterar as tabelas de cadastro de informações e outras modificações mais profundas. Em nível de gestor, as informações podem ser inseridas/consultadas além de gerar gráficos e tabelas com os dados coletados. Os demais módulos são destinados aos agentes de trânsito e policiais envolvidos e população em geral, com seus respectivos níveis de acesso ao sistema. Envolvidos nos acidentes têm a possibilidade de gerar seus boletins de ocorrência (B.O.) a partir do sistema, mediante uma chave de acesso previamente definida.

O uso de tecnologias recentes pode resultar na agilidade nos registros de acidentes de trânsito, na organização, no armazenamento e no rastreamento das informações. Da mesma forma, tem-se fácil e rápido acesso aos dados, possibilidade de execução de filtros, além de ampliação das informações levantadas, por exemplo, permitindo o georreferenciamento de cada ocorrência nas vias de trânsito. Sendo 


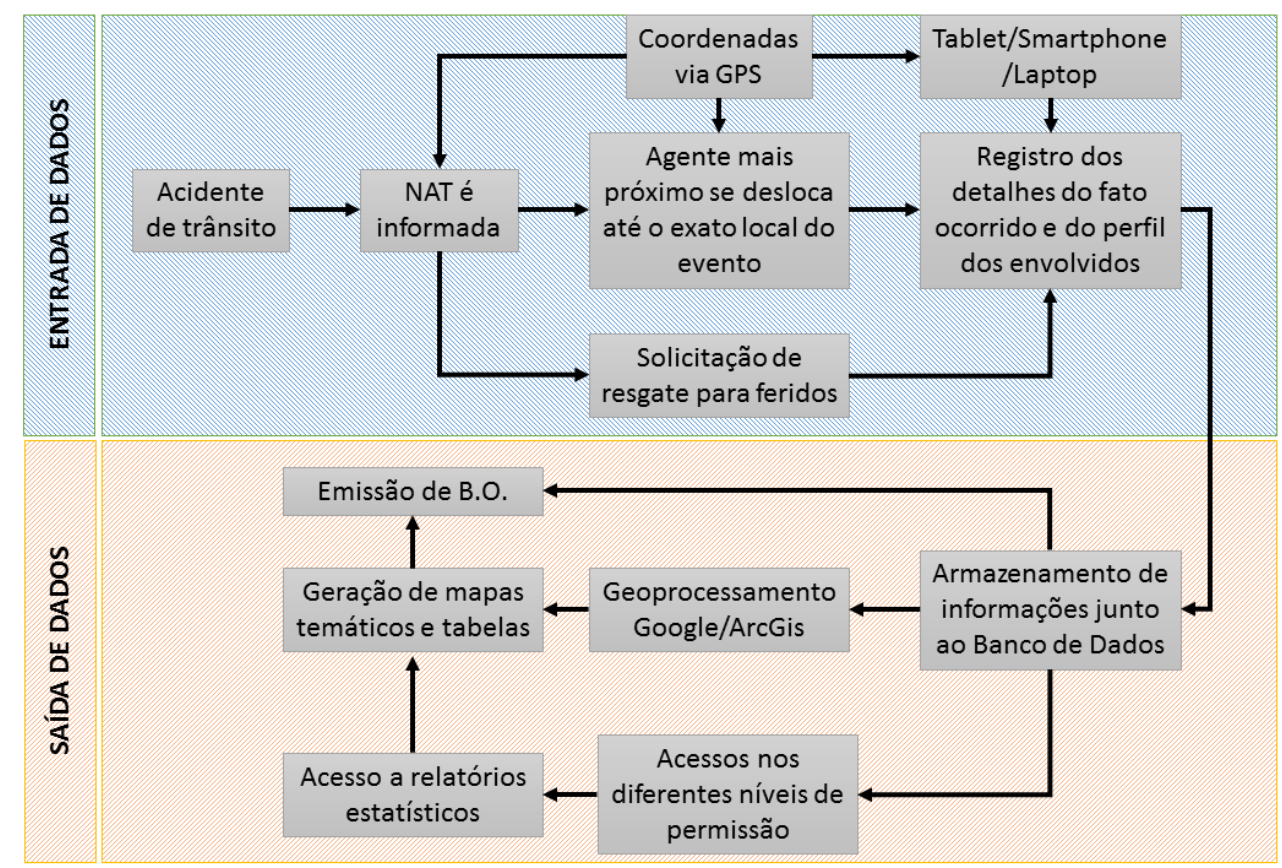

Figura 2. Conceptual Framework do sistema de gerenciamento de acidentes de trânsito proposto

Fonte:NAT - Núcleo de Agentes de Trânsito

\section{B.O. - Boletim de Ocorrência}

assim, promove uma pesquisa precisa das informações desses acidentes, a visualização dos pontos de ocorrência e sua concentração no mapa do município, oportunizando às autoridades informações para embasar uma possível tomada de decisão nas ações a serem realizadas.

O conceptual framework do sistema desenvolvido nesse trabalho (Figura 2) buscou a centralização das informações referentes aos registros de acidentes de trânsito na área urbana do município de Passo Fundo/RS. A escolha da cidade para a implementação do estudo se deu pela disponibilidade dos dados coletados pelos órgãos públicos do município, os quais atualmente são registrados através de formulários escritos e posteriormente alocados em planilhas eletrônicas. Outro fato motivador diz respeito às modificações na malha viária que o município vem sofrendo nos últimos anos. Assim, o sistema poderá atuar como balizador para avaliação das ações tomadas pelo município com relação à distribuição do tráfego urbano.

Analisando-se a forma de coleta das informações pelos agentes, optou-se pela construção de um layout responsivo capaz de ser acessado por dispositivos mobile como tablets e smartphones, tendo como meio de transmissão de dados a internet. $\mathrm{O}$ acesso à internet pode ser através de uma rede de dados disponibilizada pelas operadoras desse serviço, ou mesmo, por outra tecnologia que propicie o acesso à rede na área urbana do município. Após o levantamento de requisitos foram desenvolvidos os diagramas de caso de uso, como pode ser observado no exemplo da Figura 3, referente ao diagrama correspondente ao registro de uma ocorrência.

\subsubsection{Ferramentas utilizadas}

Observa-se que a mobilidade ganha cada vez mais espaço no mercado de dispositivos e aplicações, onde há uma tendência em disponibilizar informações para ambientes heterogêneos. No mercado de desenvolvimento de aplicativos mobile, muitos desses, são desenvolvidos especificamente para determinada versão de um sistema operacional móvel, o que resulta numa dependência entre versões e atingindo, consequentemente, uma parcela muito menor de usuários se comparado com aplicações web mobile.

Considerando esses aspectos, foram utilizadas no desenvolvimento do sistema as ferramentas HTML (HyperText Markup Language), a qual tem como principal característica a possibilidade de interligação entre outras páginas através de links (SILVA, 2012). As aplicações web mobile

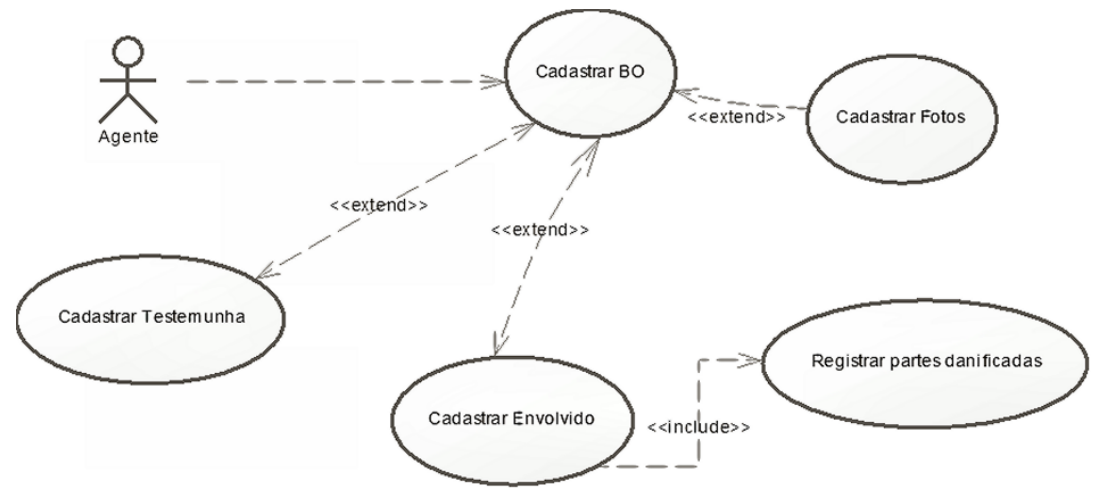

Figura 3. Diagrama de casos de uso - Registrar acidente 


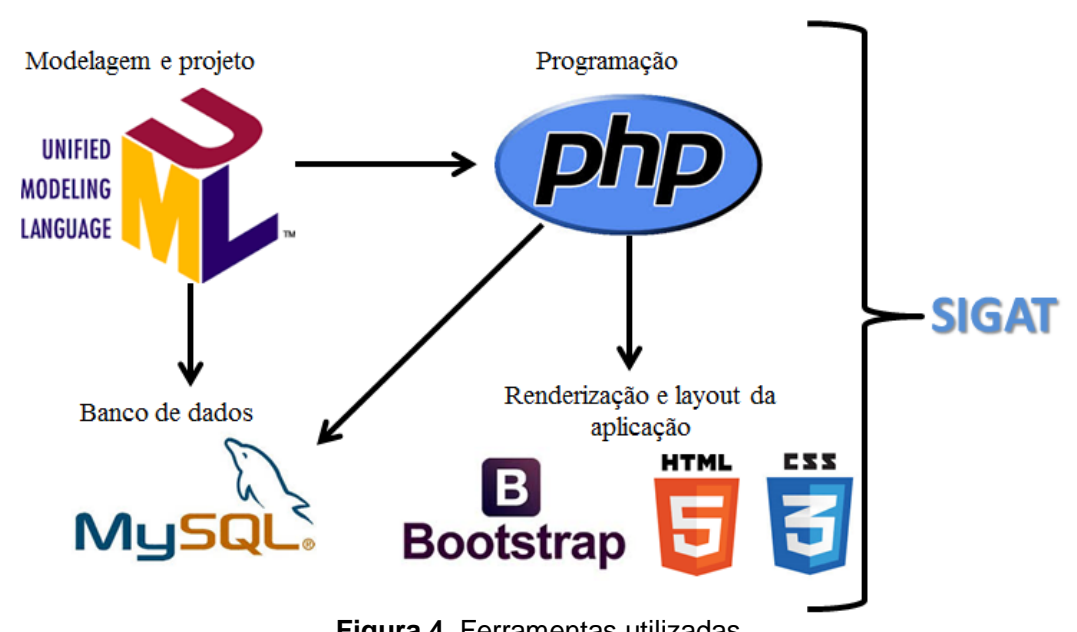

Figura 4. Ferramentas utilizadas

utilizam navegadores que possuem padronização pela W3C, que é o órgão que regulamenta os padrões do HTML. Para essa programação foi utilizada a versão 5.5 da linguagem PHP, sendo toda a programação desenvolvida com o paradigma de orientação a objeto. As principais vantagens residem na organização, no reaproveitamento de código e no custo baixo de desenvolvimento, uma vez que a compreensão é facilitada pelo conceito de objeto que se aproxima do mundo real (NIEDERAUER, 2004). Também foi utilizado o sistema CSS (Cascading Style Sheets), para a formatação e definição do layout do aplicativo, com o qual é possível controlar a aparência externa da página e fazer uma separação entre o aspecto visual e seu conteúdo. Para a implementação desse projeto foi utilizado o CSS versão 3 que apresenta significativas melhorias em relação às suas antecessoras (BUDD et al., 2006).

Por fim, em conjunto com a plataforma mobile foi utilizado um banco de dados do tipo MYSQL (versão 5.0), o qual permitiu o armazenamento dos dados do sistema e a manipulação desses através da linguagem Structured Query Language - SQL. A figura 4 ilustra o conjunto de ferramentas utilizadas no desenvolvimento do SIGAT.

\subsubsection{Análise e projeto do sistema}

A análise e levantamento de requisitos necessários para o desenvolvimento do sistema informatizado seguiu as recomendações de Guedes (2009). Essa etapa trabalha com o domínio do problema e tenta determinar "o quê" o software deve fazer e se é realmente possível desenvolvê-lo. A análise do sistema foi auxiliada pelo uso dos diagramas da UML.

Nesse caso, a UML apresenta como benefício características como a reutilização e extensão de seus diagramas durante todas as fases do projeto. Assim, concomitantemente a elaboração do estudo, bem como na fase de análise e de projeto foram construídas as documentações dos requisitos, o digrama de casos de uso e o diagrama de classes, conforme demonstrado nas Figuras 2 e 5.

Para melhor compreender o escopo geral do sistema, a Figura 5 apresenta todas as classes com os seus respectivos relacionamentos. O sistema possui um controle de acesso baseado em permissões. O administrador é responsável por cadastrar os usuários e registrar os módulos a que cada um terá de acesso. Cada ação executada no sistema irá registrar o usuário que a realizou, permitindo assim, identificar em cada registro a autoria quando necessário.
As classes representam as características de um conjunto de objetos semelhantes que podem ser agrupados e criados a partir de sua instância. Todos os objetos instanciados nessa classe possuem os mesmos atributos, no entanto, cada objeto pode possuir valor específico e diferenciado para cada atributo definido na classe. Dessa maneira, objetos são semelhantes em comportamento e atributos, mas podem ter valores próprios.

É recomendado que a construção do diagrama de classes seja efetuada durante a fase de análise, produzindose assim um modelo conceitual das informações necessárias. O modelo conceitual (HEUSER, 2009) captura as necessidades da organização em termos de armazenamento de dados independente de implementação.

\subsection{Integração do sistema com as APIs do Google}

Para integração das informações existentes no banco de dados com o mapa do município, optou-se pela utilização da API Google Earth, a qual identifica os dados através de arquivos KML ou KMZ. Através dessa API podem-se criar elementos que incluem marcadores, descrições, superposições de solo, caminhos e polígonos.

Os gráficos são gerados através da API do Google Charts, que possui uma galeria que disponibiliza inúmeros tipos de gráficos, como: quadros geográficos, gráfico de dispersão, gráficos em colunas, histograma, gráfico de barras, gráfico de pizza, entre outros. Os relatórios disponíveis no sistema permitem uma variada combinação de resultados para análise das informações de acordo com a inserção dos dados.

\subsection{Delimitação do local de implementação do sistema}

O município de Passo Fundo está situado no centronorte do Estado do Rio Grande do Sul, com coordenadas geográficas, latitude e longitude, iguais respectivamente a $28^{\circ} 15^{\prime} 46^{\prime \prime} \mathrm{S}$ e $52^{\circ} 24^{\prime} 25^{\prime \prime} \mathrm{W}$ (Figura 6). O município possui uma área de $783,42 \mathrm{~km}^{2}$ com uma população estimada de 194.432 habitantes em 2010, resultando numa densidade demográfica de 248 habitantes/ $\mathrm{km}^{2}$ e apresentando um Produto Interno Bruto (PIB) per capita de R\$ 25.618,50 ao ano, de acordo com dados do IBGE (2015).

Segundo informações do DETRAN-RS (2014), a frota de veículos para a cidade no ano de 2013 foi de mais de 87 mil unidades, resultando numa taxa aproximada de 1,8 hab./veic. Essa taxa se estabelece abaixo dos valores em 


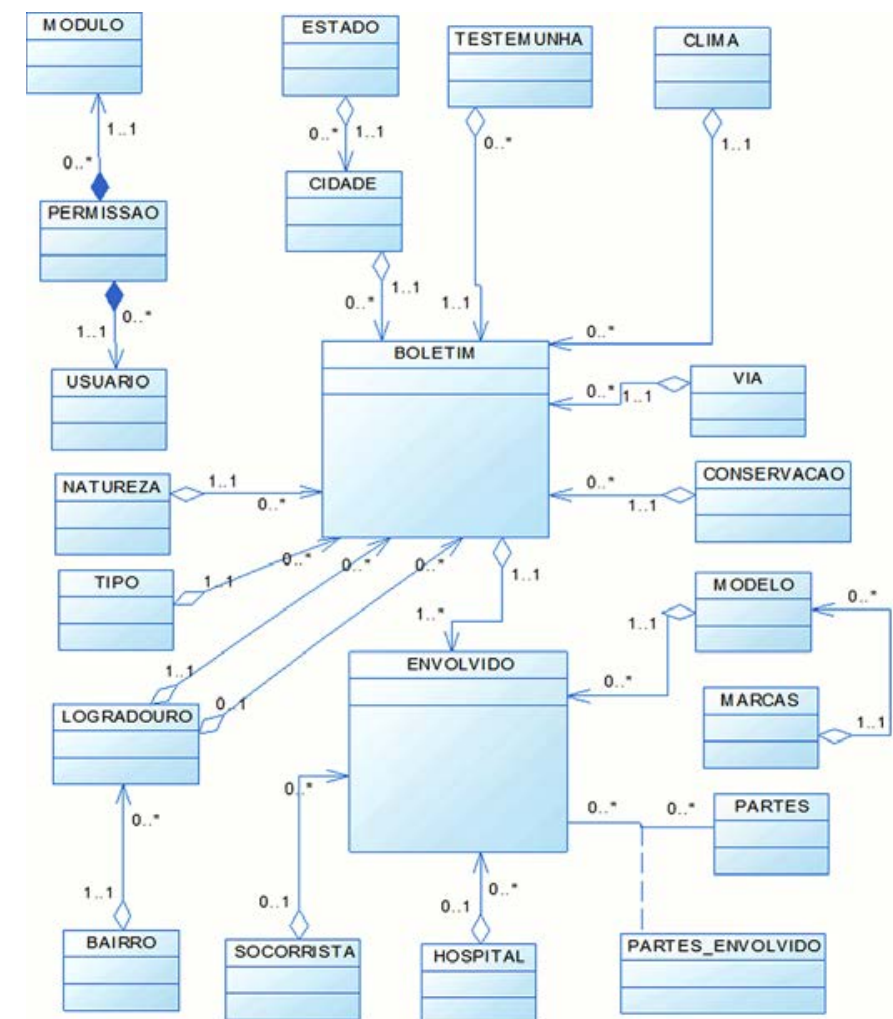

Figura 5. Diagrama de classes desenvolvida para a plataforma proposta neste estudo

nível nacional (2,4 hab./veic.) e estadual (1,9 hab./veic.), quando calculados a partir dos dados do DETRAN-RS (2014) e da Organização Mundial da Saúde (WHO, 2013). A cidade vem experimentando um crescimento anual médio de 7,1\% em sua frota nos últimos 8 anos, segundo dados apresentados pelo DENATRAN (DENATRAN, 2015). Por outro lado, a taxa de crescimento do número médio de habilitações nos últimos anos tem se mantido na ordem de 4,4\% no município (DETRAN-RS, 2015).

Os registros dos acidentes de trânsito no município vêm sendo realizados pela polícia militar e pelo Agente Fiscal de Trânsito. Entretanto, a polícia militar é comumente deslocada somente quando há vítimas resultantes do fato, ao passo que o Agente Fiscal de Trânsito fica encarregado dos acidentes em que são detectados somente danos materiais. Em ambos os órgãos, o sistema de gerenciamento de acidentes de trânsito é baseado em metodologias convencionais, como o registro de ocorrências em boletins impressos e padronizados. Isso tem se observado em outros municípios do estado e do Brasil, os quais também realizam os seus registros de forma manual, o que torna a organização dessas informações mais difícil.

\subsection{Teste do Sistema}

O processo de coleta e carga proporcionou a construção de uma base de dados consistente e possível de extrair informações gerenciais através de relatórios e filtros, proporcionando uma melhoria no acesso às informações e principalmente a centralização de todos os dados.

Na Figura 7 é apresentada uma visão geral do sistema proposto, o qual apresenta leves alterações de acessibilidade de acordo com os níveis de permissão apresentados na Figura 1. Entretanto, o sistema vem atualmente recebendo melhorias do ponto de vista de análise de dados, filtros novos vêm sendo utilizados para a elaboração de relatórios analíticos.

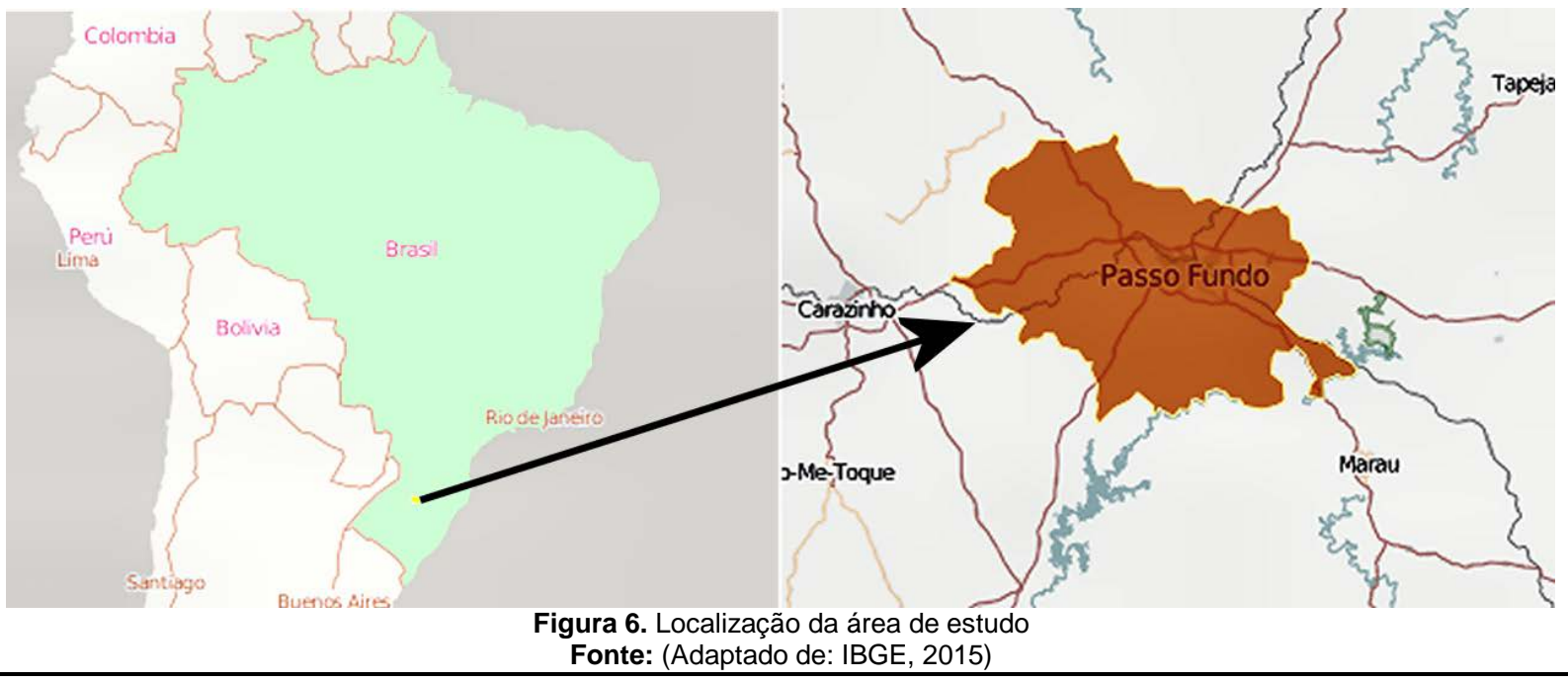




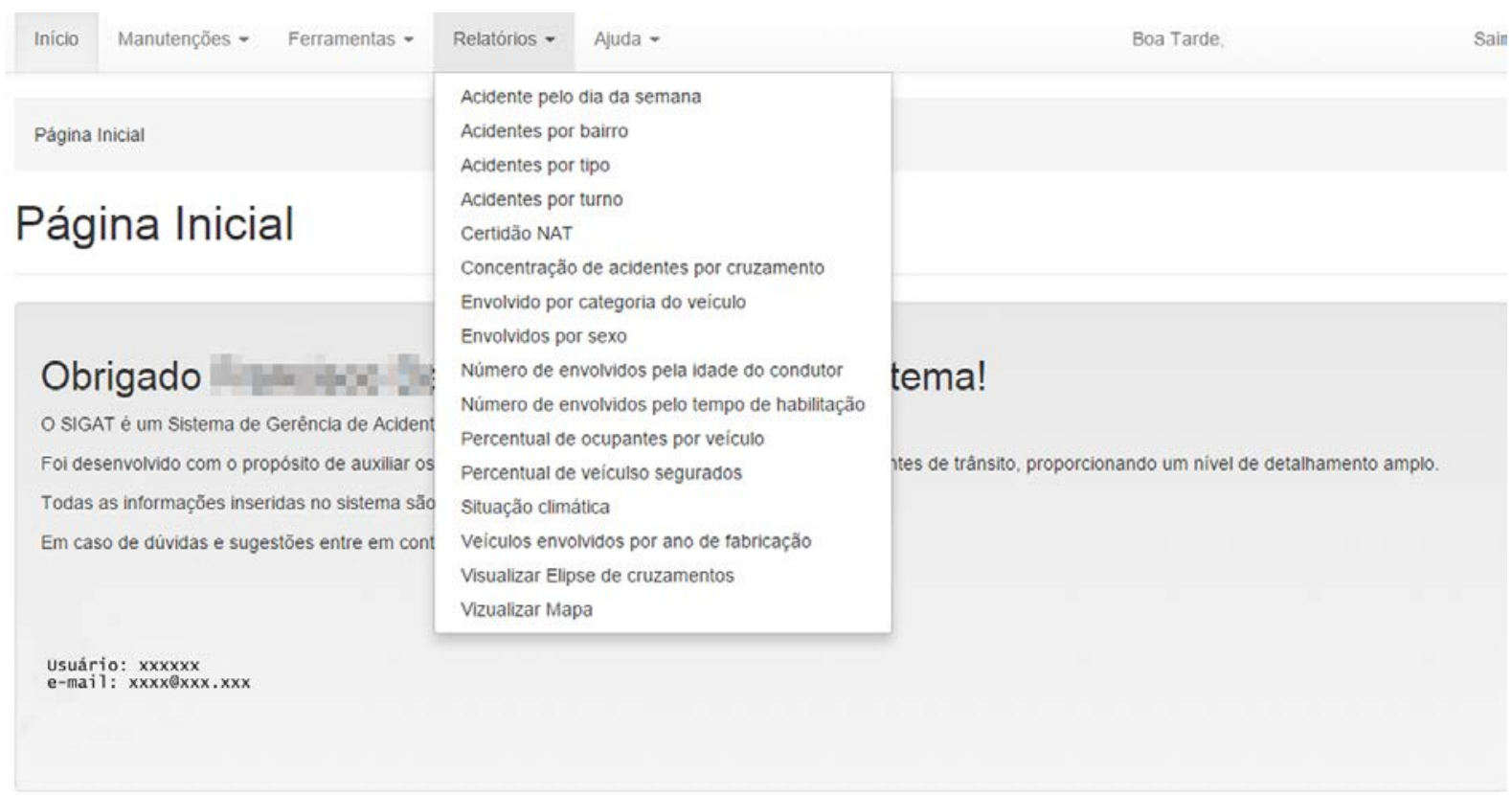

Figura 7. Visão geral do sistema desenvolvido neste estudo

\section{APRESENTAÇÃO E ANÁLISE DOS RESULTADOS}

Após o desenvolvimento do sistema e execução do processo de testes do mesmo, iniciou-se a fase de inserção de dados reais e simulação do comportamento do sistema também em ambiente real. Foram inseridos 1460 registros de acidentes de trânsito, referentes ao período compreendido entre os meses de abril a setembro de 2014, sendo que tais ocorrências foram registradas pelo Núcleo dos Agentes de Trânsito da cidade de Passo Fundo. É importante ressaltar aqui que todas as informações confidenciais sobre os usuários foram mantidas em sigilo, uma vez que o objetivo do trabalho é apresentar uma ferramenta de apoio à tomada de decisão.

A análise dos resultados apresentada a seguir foi realizada com o auxílio dos gráficos gerados pelo sistema proposto nesse estudo, levando-se em consideração a análise do perfil dos usuários envolvidos nos acidentes e as características dos sinistros.

\subsection{Análise dos dados através do sistema}

A classificação do tipo de acidente seguiu o mesmo padrão apresentado pela resolução 362 do DENATRAN (DENATRAN, 2010). Após analisar as informações coletadas no período de estudo, é possível observar que mais de $32 \%$ dos acidentes são classificados como colisão traseira, seguidos de abalroamento lateral em mesmo sentido $(20,7 \%)$ e abalroamento transversal $(19,8 \%)$, conforme demonstra a Figura 8.

A Figura 9 demonstra que mais de 64\% dos veículos envolvidos em acidentes são ocupados somente pelo motorista. Em seguida, com $24 \%$ dos registros, a ocupação dos veículos envolvidos é de duas pessoas. Diante dos dados, é perceptível a forma individual como as pessoas estão usando os meios de transporte, refletindo assim o considerável aumento na frota de veículos.

Na Figura 10 é apresentada a distribuição dos acidentes de trânsito em função da idade dos envolvidos. Observase uma grande concentração do número de envolvidos com idade superior a 50 anos seguido da faixa entre 26 a 30 anos de idade. No entanto, a análise dos resultados para os envolvidos com mais de 50 anos de idade necessita ser melhor

PERCENTUAL DE ACIDENTES POR TIPO

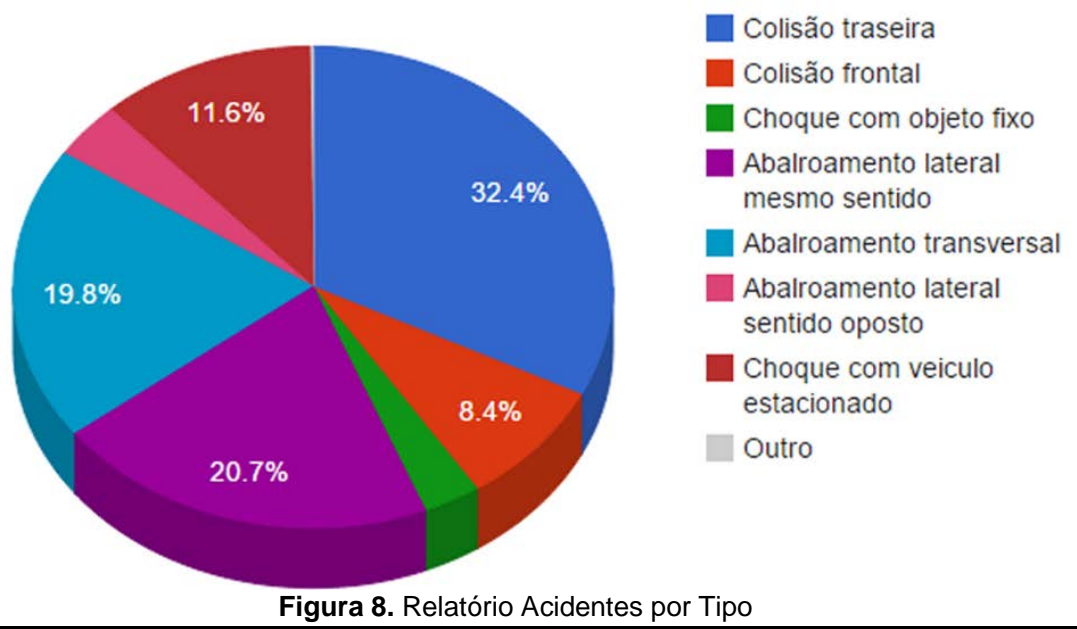




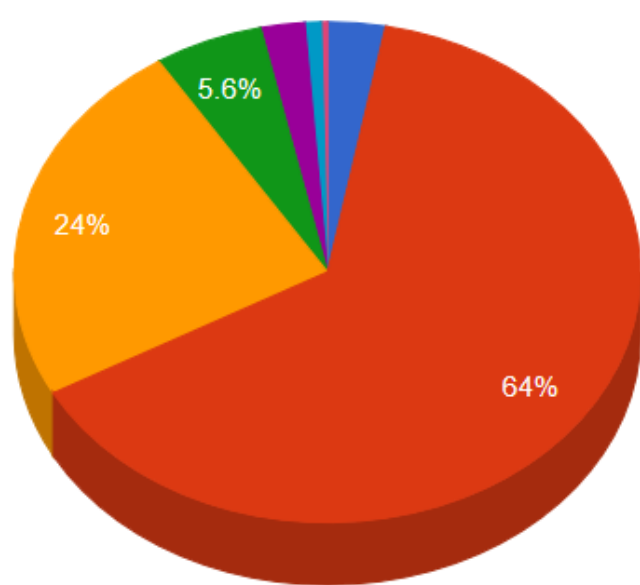

Veículo estacionado

1 Ocupante

2 Ocupantes

3 Ocupantes

4 Ocupantes

5 Ocupantes

Mais de 5 Ocupantes

Figura 9. Relatório Percentual de Ocupantes por Veículo

avaliada. Assim, a elaboração de gráficos como os apresentados nas Figuras 8, 9 e 10 vem permitindo a implementação de melhorias no sistema, no que tange à análise de resultados.

A cidade de Passo Fundo possui atualmente dois eixos viários principais, que representam as ligações entre bairros Norte/Sul e Leste/Oeste. Na Figura 11 são apresentados os dados distribuídos de acordo com as suas respectivas localizações, onde se observa que determinados cruzamentos apresentam uma concentração de acidentes. Outras informações também podem ser extraídas a partir de mapas temáticos com a indicação de locais onde os acidentes de trânsito se apresentam de forma mais concentrada. Essa visualização é possível, pois, quando o registro de acidente de trânsito é iniciado, o agente/policial tem acesso a sua localização como discutido previamente.

Em uma análise mais pontual, os resultados da localização e características dos acidentes, bem como o perfil dos usuários, podem ser analisados em sistemas mais robustos, como plataformas georreferenciadas (ex. ArcGis; TransCad; Outras). Além disso, tais dados viabilizam o suporte a análises estatísticas e ao desenvolvimento de modelos probabilísticos, com o objetivo de prever locais com maior incidência de acidentes.

Contudo, além do mapa apresentado na Figura 11 com as informações da distribuição dos acidentes no local de estudo, também foi desenvolvida uma ferramenta de análise geoespacial das ocorrências registradas como apresen- tado na Figura 12. Os locais indicados no mapa com as circunferências identificam os pontos críticos em número de acidentes de trânsito, ao passo que quanto maior for a área da circunferência, maior é o número de registros ocorridos naquele local. Concomitantemente ao uso de mapas provindos da plataforma Maps ${ }^{\circledR}$, também se faz o uso da ferramenta Street View ${ }^{\circledR}$, ambas providas pelo sistema Google. Tais análises podem apresentar elevada importância para um determinado gestor, através delas é possível observar locais críticos e ao mesmo tempo explorar as condições de contorno do local com o intuito de gerar estratégias e soluções mitigadoras.

\section{DISCUSSÃO DOS RESULTADOS}

O sistema informatizado permite validar dados de entrada evitando inconsistências e redundâncias. As informações registradas podem ser utilizadas em várias telas da aplicação, permitindo que os dados previamente cadastrados sejam reutilizados sem a necessidade de cadastrá-los novamente, proporcionando agilidade ao processo de trabalho e garantia de integridade das informações.

A informatização do processo de trabalho do Agente Fiscal de Trânsito e da Polícia Militar proporcionou facilidade, agilidade e eficiência na busca por informações relacionadas aos acidentes registrados no local de estudo. $\mathrm{O}$ sistema disponibiliza uma funcionalidade de busca, permi-

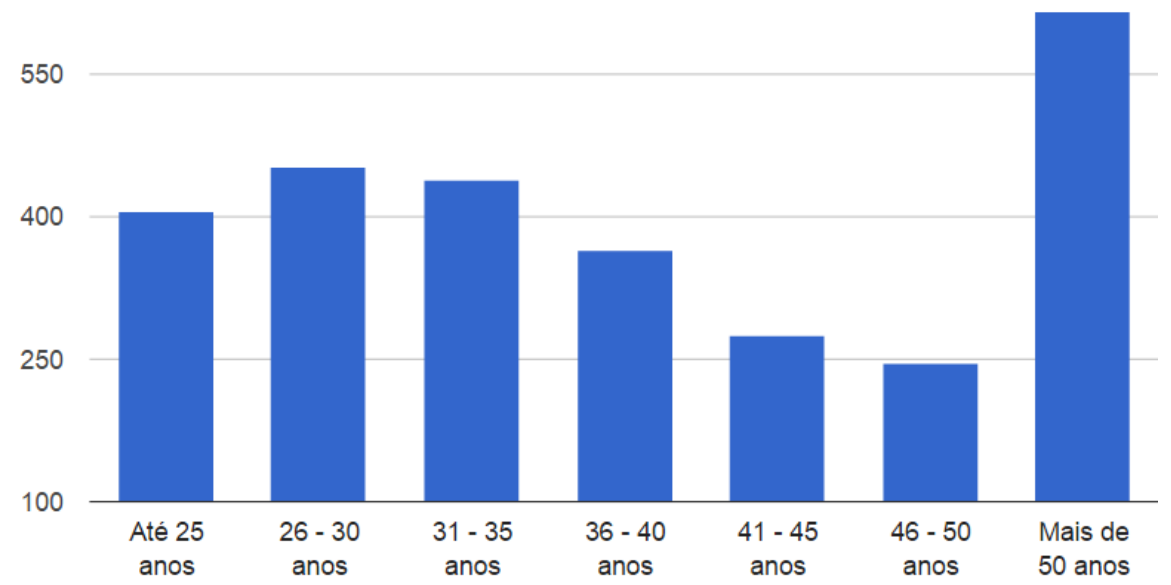

Figura 10. Distribuição do número de acidentes em função da idade dos envolvidos 


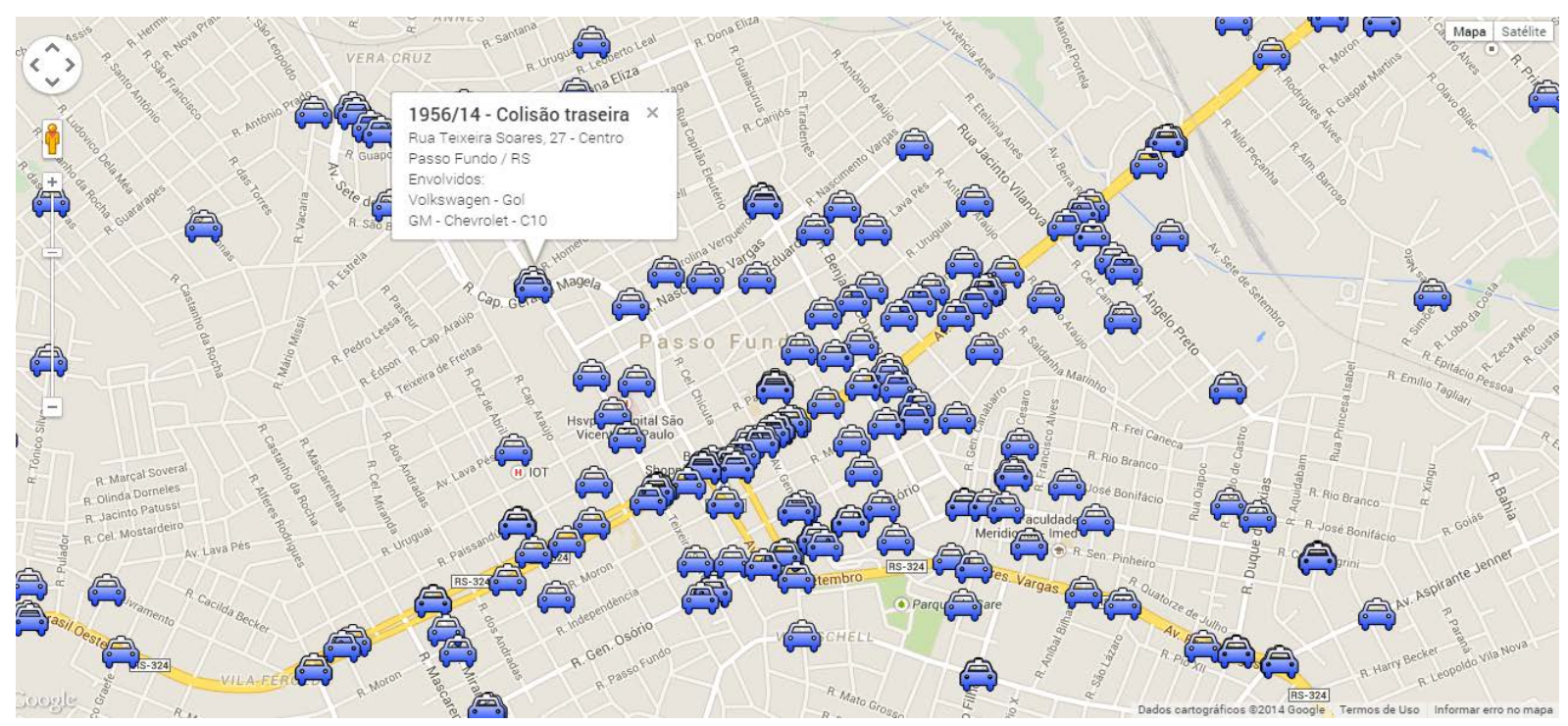

Figura 11. Visualização dos acidentes no mapa do município

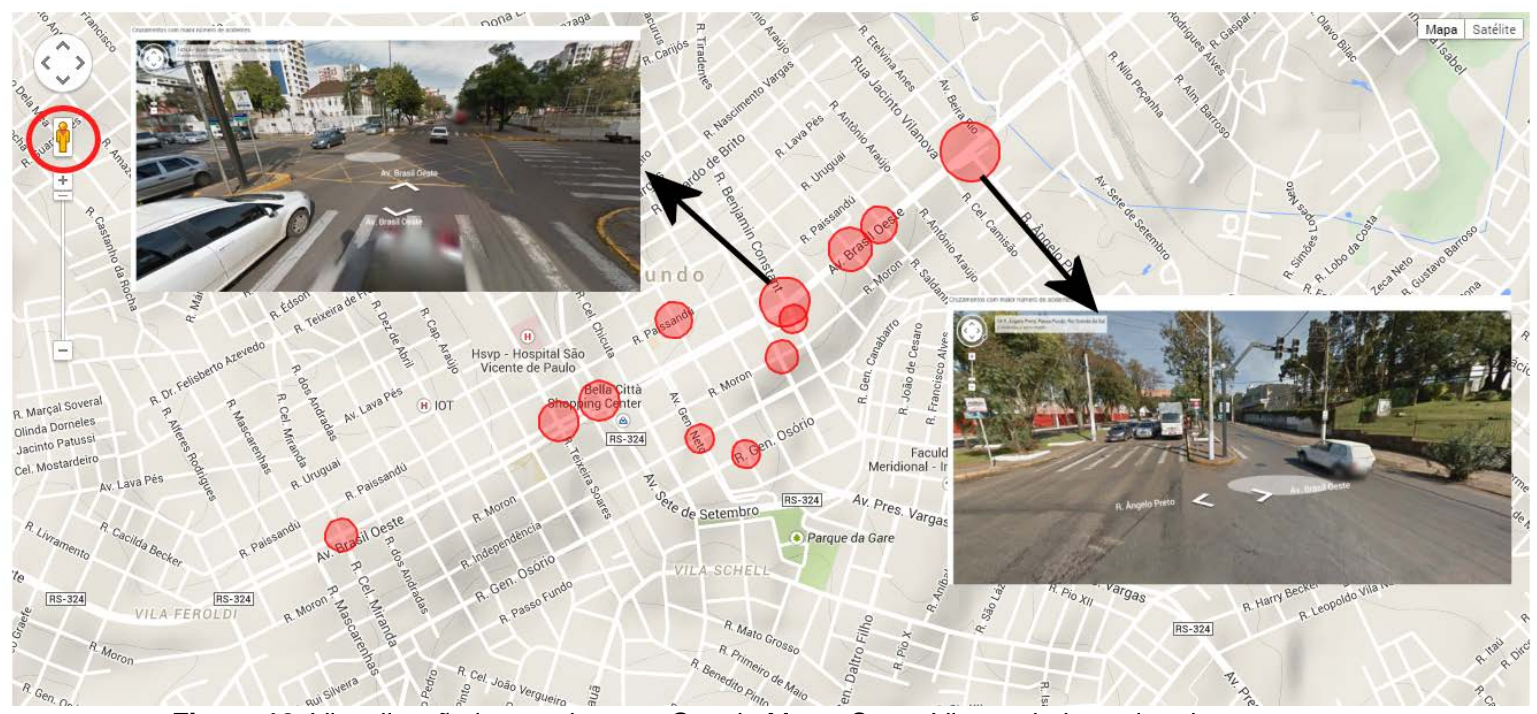

Figura 12. Visualização integrada entre Google Maps, Street View e dados coletados em campo

tindo a execução de consultas rápidas e eficazes. Anteriormente, a utilização das fichas em papel dificultava a busca pelas informações devido ao grande volume de material físico e também pelo fato de que somente eram armazenadas em planilhas algumas informações.

O lançamento das informações sobre um determinado acidente de trânsito possibilita que tomadas de decisão possam ocorrer de forma rápida, possibilitando na redução de filas causadas nesses locais. Ainda, a visualização através de gráficos e utilização da combinação de dados é de grande valia para analisar as ações de melhoria propostas para um determinado ponto de conflito. Esse tipo de ferramenta também pode ser utilizado para análise e planejamento de ações preventivas e corretivas, garantindo assertividade nos investimentos do município e possibilitando o acompanhamento dos dados históricos em relação às ações realizadas.

Outro aspecto relevante foi a identificação de informações que não estavam contempladas no processo existente, como por exemplo: data da primeira habilitação, número de ocupantes nos veículos, registro fotográfico, coordenadas geográficas, entre outros. Diante da ausência desses dados foi constatada a necessidade de ampliação das informações coletadas. Considerando a importância desses aspectos na geração de informações estatísticas, como no caso da primeira habilitação, que é possível definir o tempo de habilitação de cada condutor envolvido em acidente, gerando conhecimento e auxiliando na identificação do perfil dos condutores envolvidos em acidentes.

\section{CONCLUSÕES}

O presente estudo se concentrou na elaboração de um sistema de monitoramento de acidentes de trânsito, constituído de uma plataforma de acesso móvel e de um banco de dados, ambos vinculados às API do Google. O acesso via plataforma móvel permitiu que além de outras informações inseridas em tempo real no sistema, seja possível também realizar o registro das coordenadas geográficas do local onde o fato ocorreu. Aliado a isso, a criação do banco de dados viabilizou a concentração das informações coletadas em campo pelos diferentes órgãos fiscalizadores de trânsito, num único local, evitando-se duplicidade e inconsistências nas informações observadas em campo.

Observa-se também que a inserção das informações e seu armazenamento no banco de dados pode viabilizar um melhor gerenciamento do sistema viário, além de propiciar 
que os registros fiquem disponíveis em tempo real a todos os usuários da via. Da mesma forma, um banco de dados criado eletronicamente possibilita o uso das suas informações em futuros estudos para a elaboração de modelos probabilísticos para previsão de locais críticos. Entretanto, as ferramentas disponibilizadas no sistema, tais como infográficos e mapas temáticos, permitem uma análise preliminar dos locais de maior incidência de acidentes de trânsito, além da geração de um mapa demonstrativo de pontos com maior concentração de ocorrências.

Mesmo que o banco de dados ainda esteja sendo alimentado com informações referentes aos acidentes de trânsito ocorridos no munícipio o mesmo permitiu análises importantes. Tais análises se concentraram em avaliar a faixa etária da população envolvida nos sinistros, bem como a elaboração de mapas temáticos para análise da concentração de determinados tipos de acidentes dentro do perímetro urbano. Vale ressaltar que a plataforma é capaz de ser implementada em qualquer município brasileiro, uma vez que as coordenadas registradas são facilmente analisadas pelas ferramentas do Google.

\section{AGRADECIMENTOS}

Os autores agradecem o apoio do Núcleo de Agentes de Trânsito e a Brigada Militar do munícipio de Passo Fundo/RS pelo fornecimento das informações utilizadas nesse estudo, bem como o Google Developer Group (GDG) Norte RS pelo acesso as APIs do Google.

\section{REFERÊNCIAS}

Ansari, G. A. E Al-Shabi, M.; Modeling of Traffic Accident Reporting System through UML Using GIS. International Journal of Advanced Computer Science and Applications. v. 3, n. 6, 2012. DOI:10.14569/IJACSA.2012.030606

Budd, A.; Simonmoll, C. Criando páginas web com CSS Soluções avançadas para padrões Web. São Paulo: Pearson Prentice Hall, 2006.

DENATRAN-Departamento Nacional de Transporte. Frota de veículos. Disponível em:<www.denatran.gov.br/frota.html>. Acesso em: 21 maio. 2015.

DENATRAN-Departamento Nacional de Transporte. Consulta Municípios Integrados ao Sistema Nacional de Trânsito até 27 Mar. 2012. Disponível em

$<$ www.denatran.gov.br/municipios/orgaosmunicipais.asp\#Consul ta\%20munic\%C3\%ADpio>. Acesso em: 26 ago. 2013.

DETRAN-RS-Departamento Estadual de Trânsito do Rio Grande Do Sul. Relatório da frota em circulação no RS. Disponível em: http://www.detran.rs.gov.br/download/201410071547071_frota_ do_rs.pdf. Acesso em: 19 nov. 2014.

DETRAN-RS-Departamento Estadual de Trânsito do Rio Grande Do Sul. Perfil dos condutores do RS. Disponível em: www.detran.rs.gov.br/download/201503181437585_perfil_dos_c ondutores_do_rs.pdf Acesso em: 21 maio. 2015.

EBRAT. Boletim de Registro de Acidentes de Trânsito sem vítima. Disponível em <http://ebrat.pmerj.rj.gov.br/>. Acesso em: 18 nov. 2013.
Elmasri, R.; Navathe, S. B. Sistema de Banco de Dados. São Paulo: Pearson Addison Wesley, 2005.

França, C. H. de. et al. Sistema Integrado Georreferenciado de Controle e Monitoramento de Acidentes de Trânsito (SIGETRANS): O Projeto. $2^{\circ}$ SITEC (SIMPÓSIO DE INOVAÇÃO TECNOLÓGICA), 2011.

Guedes, G. T. A. UML 2: uma abordagem prática. São Paulo: Novatec, 2009.

Heuser, C. A. Projeto de Banco de Dados. 6. ed. Porto Alegre: Bookman, 2009.

IBGE - Instituto Brasileiro de Geografia e Estatística. Cidades@. Disponível em: <http://cidades.ibge.gov.br/xtras/home.php>. Acesso em: 25 abr. 2015.

IRF - International Road Federation. Radar - Road Accident Data Recorder Application. Disponível em: $<$ http://www.irfnet.ch/roadsafety.php?id=104>. Acesso em: 07 nov. 2013.

IRTAD - International Traffic Safety Data. Road Safety: Annual Report 2014. Disponível em: http://www.oecdilibrary.org/docserver/download/7514011e.pdf?expires=1416447 852\&id=id\&accname=guest\&checksum=E3FAEA31251EDBC1 AEF79FEE2402FCDC. Acesso em: 19 nov. 2014.

Medeiros, E. S. de. Desenvolvendo software com UML 2.0: definitivo. São Paulo: Pearson Makron Books, 2004.

Niederauer, J. PHP para quem conhece PHP - Recursos avançados para a criação de Websites dinâmicos. São Paulo: Novatec editora, 2004.

Prado, N. Volta Redonda: Guarda irá realizar registro de acidente em tablet. Disponível em < http://diariodovale.uol.com.br/noticias/0,76252,Volta-Redonda:Guarda-ira-realizar-registro-de-acidente-emtablet.html\#axzz2lxRD3Jge>. Acesso em: 20 nov. 2013.

Queiroz, M. P.; Loureiro, C. F. G.; Cunto, F. J. C. Georreferenciamento do sistema de informações de acidentes de trânsito de Fortaleza (SIAT-FOR): aperfeiçoamento e vantagens. Anais do XVIII Congresso de Pesquisa e Ensino em Transportes - ANPET. Associação Nacional de Pesquisa e Ensino e Transportes, Florianópolis, 2003, p. 53-60.

Silva, M. S. Jquery Mobile: desenvolva aplicações web para dispositivos móveis com HTML 5, CSS 3, Ajax, Jquery e Jquery UI. São Paulo: Novatec, 2012.

Waiselfisz, J. J. Mapa da Violência 2013: Acidentes de Trânsito e Motocicletas. Rio de Janeiro, 2013. Disponível em < www.mapadaviolencia.org.br/pdf2013/mapa2013_transito.pdf > Acesso em: 22 de julho de 2015.

WHO - World Health Organization. Global status report on road safety 2013: supporting a decade of action. Luxemburgo, 2013. 318p. Disponível em <

www.who.int/violence_injury_prevention/road_safety_status/201 3/en/ > . Acesso em: 22 de julho de 2015. 